\title{
Absence of intrinsic post-zygotic incompatibilities in artificial crosses between sympatric coregonid species from upper Lake Constance
}

\author{
R. ECKMANN* \\ Department of Biology, Limnological Institute, University of Konstanz, D-78464, Konstanz, \\ Germany
}

\begin{abstract}
A full factorial crossing experiment with five females and five males of each of two coregonid species from upper Lake Constance was used to test for intrinsic post-zygotic incompatibilities during early ontogeny. Up until shortly before hatching, there was no difference in embryo mortality between homo and heterologous crosses. A maternal effect on mortality was found in both species, but paternal effects and female-male interactions were absent. Thus, genetic incompatibility during early ontogeny does not appear to prevent introgressive hybridization, suggesting that genetic divergence between these species is maintained primarily by pre-zygotic barriers. The recent genetic homogenizations of coregonid species flocks in European alpine lakes may have been caused by a flattening of adaptive landscapes through eutrophication, but intensive stocking with larvae obtained in hatcheries from artificially fertilized eggs is also likely to be a contributing factor. To safeguard diversity among sympatric coregonids, it is important to re-establish ecological conditions conducive to species divergence and to revise traditional management strategies.
\end{abstract}

Key words: biodiversity; eutrophication; introgressive hybridization; speciation reversal; stocking.

\section{INTRODUCTION}

Coregonids provide a classical example of sympatric speciation. They colonized European alpine lakes only recently, after the last glaciation some 10-12 000 years ago (Keller \& Krayss, 2000). Genetic divergence of species (sometimes referred to as forms or ecotypes) within and between lakes can best be explained by a species-flock model (Douglas et al., 1999). Through replicate adaptive radiations, similar patterns of diversification, for example, into densely gill-rakered zooplankton feeders and sparsely rakered invertebrate feeders occurred in independent lineages in many European alpine lakes (Hudson et al., 2011).

Genetic divergence between sympatric coregonid species is low and is generally thought to be maintained via pre-zygotic barriers, i.e. different spawning places and times (Vonlanthen et al., 2009). Post-zygotic incompatibilities, both extrinsic and

Author to whom correspondence should be addressed. Tel.: +49 7531 882828; email: reiner.eckmann@uni-konstanz.de 
intrinsic, however, can result from ecological speciation (Schluter, 2009). These may become crucially important when the selective forces that led to ecological differentiation and the development of associated pre-zygotic barriers are relaxed, allowing for increased introgressive hybridization. Under these circumstances, without post-zygotic incompatibility barriers, increased gene flow between sympatric species will reduce ecological and genetic divergence (Vonlanthen et al., 2012) and may lead to speciation reversal (Seehausen, 2006).

The eutrophication of European alpine lakes during the second half of the 20th century has contributed to both species loss and speciation reversal (Vonlanthen et al., 2012). Species loss was caused by deterioration in spawning ground quality following excessive sedimentation of organic matter. Speciation reversal was facilitated by enhanced secondary production, leading to a loss of functional diversity among sympatric species, i.e. reduced range in gill-raker numbers, which is a heritable trait in coregonids (Ostbye et al., 2006; Roesch et al., 2013). In Lake Constance, for example, the gill-raker numbers of two sympatric zooplanktivorous species converged from mean values of 36 and 41, respectively, to 35 during the eutrophic period. As genetic differentiation among Lake Constance coregonid species declined since pre-eutrophication times, and private alleles of an extinct species are found in three extant species (Vonlanthen et al., 2012), introgressive hybridization must have occurred in parallel.

The degree of genetic incompatibility has been evaluated in allopatric North American coregonids (Lu \& Bernatchez, 1998; Rogers \& Bernatchez, 2006) and in native and introduced coregonid lineages in Austrian lakes (Winkler et al., 2011; Pamminger-Lahnsteiner et al., 2012), but incompatibilities between sympatric coregonids from European alpine lakes have not yet been studied experimentally. Hence, the first aim of this study was to test for intrinsic post-zygotic incompatibilities in European coregonids, using the inshore-spawning Coregonus macrophthalmus Nüsslin 1882 and pelagic-spawning Coregonus wartmanni (Bloch 1784) of upper Lake Constance as examples.

Even when introgression between species is possible, offspring viability may differ depending on the species of the male and female. Such effects are generally attributed to maternal influence, because the maternal contribution to progeny comprises both genetic and non-genetic material in the form of yolk (Rideout et al., 2004). Indeed, maternal effects on survival and growth during early life-history phases, mediated by egg size, yolk volume and fatty acid content, have been shown in a variety of species (Sarvala \& Helminen, 1995; Chambers \& Leggett, 1996; Rideout et al., 2005). Paternal effects, on the other hand, have been studied less intensively, because the potential contribution to progeny is restricted to nuclear genetic material. There are, however, several studies indicating paternal effects on fertilization success and performance during early life history (Vøllestad \& Lillehammer, 2000; Rideout et al., 2004; Wedekind \& Müller, 2004; Probst et al., 2006; Huuskonen et al., 2009; Kroll et al., 2013), although paternal effects in crosses between sympatric coregonids have not been studied so far. Hence, the second aim of this study was to look for maternal, paternal and breeder interaction effects on embryonic development in crosses between the two coregonid species. To pursue these aims, a study was designed in which five female and five male fish from each species were crossbred in all possible combinations, resulting in 10 half-sibling families per female and 10 half-sibling families per male, i.e. a total of 100 crosses. 


\section{MATERIALS AND METHODS}

Coregonus wartmanni and $C$. macrophthalmus make up the bulk of commercial catches in upper Lake Constance ( $472 \mathrm{~km}^{2}$ surface area, $254 \mathrm{~m}$ maximum and $101 \mathrm{~m}$ mean depth). From 1960 to 2014 , mean \pm S.D. yields were $414 \pm 225 \mathrm{t} \mathrm{year}^{-1}$ for $C$. wartmanni and $133 \pm 84 \mathrm{t} \mathrm{year}^{-1}$ for $C$. macrophthalmus). During the growing season, both species are often co-harvested from the pelagic zone where they feed on zooplankton, but at spawning time they segregate into their pelagic (C. wartmanni) and littoral (C. macrophthalmus) spawning sites (Eckmann \& Rösch, 1998).

For this study, C. wartmanni were sampled with floating gillnets and C. macrophthalmus with bottom-set gillnets on the same day of the spawning season in 2008. Upon retrieval from the nets, the fish were immediately sacrificed with a sharp blow to the head to avoid excessive losses of eggs and milt due to spontaneous body flexion. The fishes were transported on ice and processed within $1 \mathrm{~h}$ of capture. Five female and five male fish of similar size were selected for each species, aiming at minimizing size differences within species. They were measured (total length, $L_{\mathrm{T}}, 0.5 \mathrm{~cm}$ ), weighed (to $1 \mathrm{~g}$ ) and scales were taken for age determination. Females were weighed only after all eggs had been stripped because some eggs were inevitably lost during capture and transport.

Eggs were stripped first into dry plastic bowls and 10 sub-samples per female of similar volume were subsequently distributed into dry glass cups that were partly immersed in crushed ice. Milt was also collected into glass cups and stored as above. Using a graduated pipette, $3-5 \mu \mathrm{l}$ of milt from each male was added to one sub-sample of eggs from each female. Immediately afterwards, $10 \mathrm{ml}$ of pre-cooled water $\left(4^{\circ} \mathrm{C}\right)$ was added to each glass cup and eggs and milt were stirred gently. After $10 \mathrm{~min}$, eggs were washed with pre-cooled water several times. Each egg sample was further subdivided into three replicates of similar egg numbers that were transferred to glass Petri dishes of $9 \mathrm{~cm}$ inner diameter. Incubation of coregonid eggs in Petri dishes has been used previously by Rojas-Beltran \& Gillet (1995) and Wedekind \& Müller (2004). Sufficient water was added to cover the eggs completely, and the dishes were closed with a glass lid. Crosses were randomly assigned to six groups of 15 and one group of 10 crosses. Within each group, the three replicates per cross were allocated to one of the three racks that were distributed randomly on shelves in a temperature-controlled room $\left(4-5^{\circ} \mathrm{C}\right)$ with an $08 \mathrm{~L}: 16 \mathrm{D}$ regime. Replicates were employed to account for small differences in temperature and light intensity inside the incubation room that might influence embryo development.

During the fertilization procedure, a further duplicate egg sample was retained from each female. After water hardening, these eggs were transferred to a v-shaped plastic rack of $15 \mathrm{~cm}$ length until no more eggs could be accommodated in a straight line. Average egg diameter was then calculated from rack length and egg number. The eggs were then dried at $80^{\circ} \mathrm{C}$ and the average dry mass was determined.

Embryos were checked daily and dead embryos were removed and counted. Water was completely changed with increasing frequency during the incubation period, initially once every 3 days increasing to daily during the final 2 weeks. During peak hatching, five to six larvae were sampled from each Petri dish and deep-frozen. They were later thawed, measured for $L_{\mathrm{T}}$ under a dissecting microscope with image analysis software and average dry mass per replicate was measured after drying to constant mass at $60^{\circ} \mathrm{C}$.

The $L_{\mathrm{T}}$ and mass of spawners were analysed with two-way ANOVAs with species and sex as nominal factors. One-way ANOVAs were used to compare egg dry mass and diameter between species. Average egg dry mass per Petri dish was compared between species using one-way ANOVA. A possible influence of egg number per Petri dish on early embryo mortality was tested with Spearman rank correlation within each maternal family for both species. Average mortality rates among each group of three racks that harboured the replicates of 15 different crosses (10 different crosses in the last group of three racks) were compared by one-way ANOVA or Kruskal-Wallis ANOVA. Considering differences in $L_{\mathrm{T}}$ and mass of spawners and in egg dry mass between species, embryo mortality and $L_{\mathrm{T}}$ and mass of larvae at hatching were analysed separately for each maternal species. Mortality data were $\ln$ transformed prior to analysis to meet model assumptions of normality. Mortality of all homo and heterologous crosses were compared between species using one-way ANOVA, and within each species mortality between homo and heterologous crosses was compared in the same way. Maternal and paternal effects 
were analysed with two-way ANOVAs with female number and male species as nominal factors and male individuals nested in male species, considering all interactions. $L_{\mathrm{T}}$ and dry mass of larvae at hatching were analysed in the same way. When factors and interactions were not significant, they were excluded from the final models. The relation between mean egg dry mass and mean dry mass of larvae per female was compared between species using ANCOVA with female species as covariate. All analyses were carried out in JMP 7.0.1 (SAS Institute; www.sas.com) and significance was set at $P<0.05$ in all analyses.

\section{RESULTS}

Captured C. wartmanni were on average $c .1$ year older than C. macrophthalmus (nine fish of age 3 years and one fish of age 4 years $v$. six fish of age 2 years and four fish of age 3 years, respectively) (Table I). Coregonus macrophthalmus were significantly larger (mean \pm S.D.: $35 \cdot 2 \pm 1 \cdot 0$ v. $33.8 \pm 1 \cdot 3 \mathrm{~cm}$, ANOVA, $F_{1,18}=7 \cdot 30, P<0 \cdot 05$ ) and heavier $\left(337 \pm 38\right.$ v. $288 \pm 34 \mathrm{~g}$, ANOVA, $\left.F_{1,18}=9 \cdot 17, P<0 \cdot 01\right)$ than $C$. wartmanni, but there was no apparent size difference between sexes in either species (Table I). Egg dry mass was significantly higher in $C$. macrophthalmus (mean \pm S.D.: $2 \cdot 24 \pm 0 \cdot 15$ v. $1.82 \pm 0.15 \mathrm{mg}$, ANOVA, $F_{1,8}=15.88, P<0.001$ ), and the same was found for egg diameter $\left(2.69 \pm 0.06\right.$ v. $2.47 \pm 0.03 \mathrm{~mm}$, ANOVA, $\left.F_{1.8}=46.94, P<0.001\right)$. Overall mean egg number per Petri dish was 94 . The smaller $C$. wartmanni eggs were mean \pm S.D. $105 \pm 21$ per dish compared with $83 \pm 24$ C. macrophthalmus eggs, adding up to $c .15600$ C. wartmanni eggs and 12500 C. macrophthalmus eggs incubated in total. Given the higher dry mass per egg in C. macrophthalmus, mean \pm S.D. egg dry mass per Petri dish did not differ between species (C. wartmanni: $191 \pm 38 \mathrm{mg}$, C. macrophthalmus: $185 \pm 53$, ANOVA, $F_{1,298}=1 \cdot 59, P>0 \cdot 05$ ).

Hatching began after $c$. 80 days of embryonic development and continued for $c$. 20 days across all families. Embryo mortality showed a bimodal pattern. The first phase occurred during the first 5-6 weeks after fertilization, and the second phase started $c$. 84 days post-fertilization when embryos began to hatch (Fig. 1). When the first mortality episode ended, heartbeat had started in the surviving embryos and blood circulation was visible in the vitelline vein. When the second phase of mortality began, pectoral-fin flutter and eye movement were visible in almost all surviving embryos.

In embryos from $C$. wartmanni mothers, the early bout of mortality accounted for $>60 \%$ of the total mortality recorded, whereas in embryos of $C$. macrophthalmus mothers between 30 and $90 \%$ of the total mortality occurred during this phase (Fig. 1). The late mortality episode, shortly before and during hatching, was most likely due to suboptimal incubation conditions in the shallow Petri dishes. Upon hatching of embryos, an oily film formed on the water surface, which probably impeded the essential supply of oxygen during the last phase of development, leading to death of embryos either inside the chorion or shortly after hatching. The number of eggs per Petri dish was not related to early mortality in neither family of both species (Spearman $r_{\mathrm{s}}<0 \cdot 317=r_{28}$, $P>0.05$ in all cases). Average early mortality did not differ among the three racks per group $(P>0.05$ in all cases) and therefore results from the three replicates per cross were pooled for further analysis.

Mean early mortality across all homo and heterologous crosses did not differ between embryos of $C$. wartmanni (16.6\%, range $11 \cdot 1-26 \cdot 1 \%)$ and $C$. macrophthalmus mothers $\left(16.0 \%\right.$, range $3.9-32.2 \%$ ) (ANOVA, $F_{1,98}=2 \cdot 13, P>0.05$ ) nor were the variances significantly different (Bartlett test, $\chi^{2}=5 \cdot 67, P>0 \cdot 05$ ). Early mortality of female 
TABLE I. Size [total length $\left(L_{\mathrm{T}}\right)$ and mass] and age of spawners used in the homo and heterologous crosses, egg size indices (duplicate sample dry mass and diameter) and mean \pm S.D. $L_{\mathrm{T}}$ and dry mass of larvae for each female $(\mathrm{F} ; \mathrm{M}$, male)

\begin{tabular}{|c|c|c|c|c|c|c|c|c|}
\hline $\begin{array}{l}\text { Species } \\
\text { code* }^{*}\end{array}$ & Sex & $\begin{array}{c}L_{\mathrm{T}} \\
(\mathrm{cm})\end{array}$ & $\begin{array}{l}\text { Mass } \\
(\mathrm{g})\end{array}$ & $\begin{array}{c}\text { Age } \\
\text { (years) }\end{array}$ & $\begin{array}{c}\text { Egg dry } \\
\text { mass } \dagger \\
(\mathrm{mg})\end{array}$ & $\begin{array}{c}\text { Egg } \\
\text { diameter } \dagger \\
(\mathrm{mm})\end{array}$ & $\begin{array}{c}\text { Larvae } \\
L_{\mathrm{T}} \neq \\
(\mathrm{mm})\end{array}$ & $\begin{array}{c}\text { Larvae dry } \\
\text { mass } \S \\
(\mathrm{mg})\end{array}$ \\
\hline W1 & F & $32 \cdot 5$ & 244 & 3 & $1 \cdot 95 / 1 \cdot 94$ & $2 \cdot 50 / 2 \cdot 50$ & $10 \cdot 0 \pm 0 \cdot 1$ & $1 \cdot 43 \pm 0 \cdot 10$ \\
\hline W2 & F & $33 \cdot 0$ & 255 & 3 & $1 \cdot 61 / 1 \cdot 61$ & $2 \cdot 46 / 2 \cdot 42$ & $9 \cdot 6 \pm 0 \cdot 1$ & $1.09 \pm 0.04$ \\
\hline W3 & $\mathrm{F}$ & $35 \cdot 5$ & 360 & 4 & $1.67 / 1.66$ & $2 \cdot 46 / 2 \cdot 42$ & $9 \cdot 6 \pm 0 \cdot 2$ & $1 \cdot 14 \pm 0.04$ \\
\hline W4 & F & $33 \cdot 6$ & 282 & 3 & $1.95 / 1.66$ & $2 \cdot 50 / 2 \cdot 50$ & $9 \cdot 9 \pm 0.2$ & $1.40 \pm 0.07$ \\
\hline W5 & $\mathrm{F}$ & $36 \cdot 0$ & 292 & 3 & $1.91 / 1.91$ & $2 \cdot 50 / 2 \cdot 46$ & $9 \cdot 8 \pm 0 \cdot 3$ & $1.30 \pm 0.09$ \\
\hline $\mathrm{W} 1 \mathrm{~m}$ & M & $32 \cdot 0$ & 262 & 3 & & & & \\
\hline $\mathrm{W} 2 \mathrm{~m}$ & M & $35 \cdot 0$ & 323 & 3 & & & & \\
\hline $\mathrm{W} 3 \mathrm{~m}$ & M & $33 \cdot 5$ & 281 & 3 & & & & \\
\hline $\mathrm{W} 4 \mathrm{~m}$ & M & $33 \cdot 5$ & 301 & 3 & & & & \\
\hline W5 m & M & $33 \cdot 0$ & 275 & 3 & & & & \\
\hline M1 & $\mathrm{F}$ & $36 \cdot 0$ & 350 & 2 & $2 \cdot 03 / 2 \cdot 05$ & $2 \cdot 63 / 2 \cdot 68$ & $10 \cdot 5 \pm 0 \cdot 2$ & $1.47 \pm 0.08$ \\
\hline M2 & F & $36 \cdot 0$ & 281 & 2 & $2 \cdot 21 / 2 \cdot 22$ & $2 \cdot 63 / 2 \cdot 63$ & $10 \cdot 3 \pm 0 \cdot 3$ & $1.62 \pm 0.06$ \\
\hline M3 & $\mathrm{F}$ & $35 \cdot 0$ & 316 & 2 & $2 \cdot 36 / 2 \cdot 37$ & $2 \cdot 78 / 2 \cdot 73$ & $10 \cdot 5 \pm 0 \cdot 3$ & $1.74 \pm 0.08$ \\
\hline M4 & $\mathrm{F}$ & $33 \cdot 5$ & 286 & 3 & $2 \cdot 11 / 2 \cdot 12$ & $2 \cdot 68 / 2 \cdot 63$ & $10 \cdot 1 \pm 0 \cdot 3$ & $1 \cdot 51 \pm 0 \cdot 11$ \\
\hline M5 & $\mathrm{F}$ & $36 \cdot 5$ & 390 & 2 & $2 \cdot 45 / 2 \cdot 44$ & $2 \cdot 78 / 2 \cdot 78$ & $10 \cdot 8 \pm 0 \cdot 2$ & $1.73 \pm 0.08$ \\
\hline M1 m & M & $35 \cdot 0$ & 338 & 3 & & & & \\
\hline $\mathrm{M} 2 \mathrm{~m}$ & M & $34 \cdot 0$ & 324 & 2 & & & & \\
\hline M3 m & M & $34 \cdot 5$ & 334 & 3 & & & & \\
\hline M4 m & M & $36 \cdot 0$ & 397 & 2 & & & & \\
\hline M5 m & M & $35 \cdot 0$ & 350 & 3 & & & & \\
\hline
\end{tabular}

*Codes used in Fig. 2 (W, Coregonus wartmanni; M, Coregonus macrophthalmus; m, male).

$\dagger$ Measured in duplicate for each female with 54-62 eggs pooled per sample.

$\ddagger$ Averaged across individual lengths of five to six larvae per replicate and 10 crosses per female.

$\S$ Averaged across mean dry mass per replicate and 10 crosses per female.

C. wartmanni $\times$ male $C$. wartmanni crosses averaged $18.4 \%$ (range: $4.5-38.0 \%$ ) and was $14.9 \%$ (range: $2 \cdot 8-36.9 \%$ ) for female C. wartmanni $\times$ male C. macrophthalmus, and these values did not differ significantly (ANOVA, $F_{1,48}=1.62, P>0.05$ ). For female $C$. macrophthalmus $\times$ male $C$. macrophthalmus crosses, early mortality averaged $18.5 \%$ (range: $1.9-45.5 \%$ ) and was $13.5 \%$ (range: $1.4-41.4 \%$ ) for female $C$. macrophthalmus $\times$ male $C$. wartmanni, and these values did not differ either (ANOVA, $\left.F_{1,48}=0.55, P>0.05\right)$. Maternal effects on early mortality were highly significant in both species $\left(C\right.$. wartmanni: ANOVA, $F_{4,45}=7 \cdot 18, P<0 \cdot 001$; $C$. macrophthalmus: $\left.F_{4,45}=54.32, P<0.001\right)$. Paternal effects by contrast could not be detected (ANOVA, $\left.F_{4,32}=1.39, P>0.05 ; F_{4,32}=1.09, P>0.05\right)$, but the power of these tests were only $0 \cdot 38$ and $0 \cdot 29$, respectively.

The $L_{\mathrm{T}}$ and dry mass of larvae at hatching (for overall means per female, see Table I) differed significantly among females in both species (ANOVA, $P<0.001$ in all cases), and additionally in larvae of $C$. macrophthalmus mothers, male species showed a significant influence on $L_{\mathrm{T}}$ (mean \pm S.E.: $10 \cdot 36 \pm 0.05 \mathrm{~mm}$ for $C$. wartmanni males v. $10.53 \pm 0.05$ for $C$. macrophthalmus males, ANOVA, $\left.F_{1,44}=5.59, P<0.05\right)$. The 


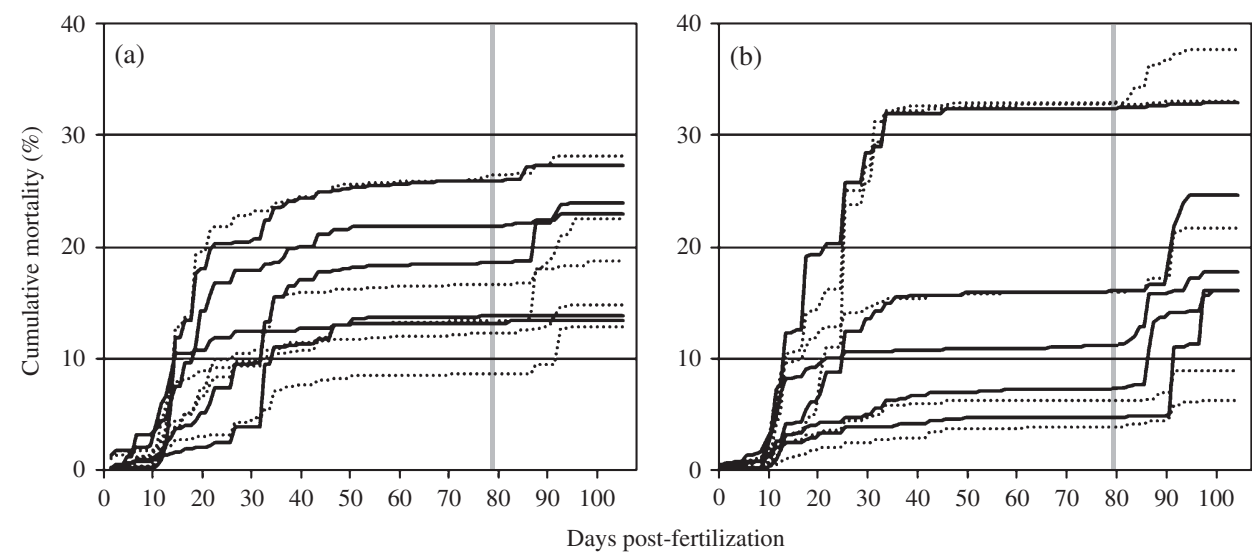

FIG. 1. (a) Average cumulative mortality up until hatching of embryos from each of five Coregonus wartmanni females sired by either five homologous (__ or heterologous (......) fathers and (b) the same for embryos of Coregonus macrophthalmus females. $\square$, day 79 post-fertilization, when early mortality for each of the 100 crosses was assessed.

relationship between dry mass of larvae at hatching and egg dry mass did not differ between species (ANCOVA, $P>0 \cdot 05$ ), and the relationship was highly significant across both species $\left(r^{2}=0.978, P<0.001\right)$.

\section{DISCUSSION}

No intrinsic post-zygotic incompatibilities were apparent in artificial crosses between C. wartmanni and C. macrophthalmus and such effects are probably therefore not relevant to the reproductive isolation of these sympatrically evolved coregonid species. No significant difference was observed in mortality during early embryonic development between homo or heterologous crosses in both species. Mortality rates could only be quantified up until shortly before hatching, but this does not compromise the main conclusion drawn from this study. Early mortality as defined here integrates both fertilization failure and dysfunction during early embryonic development, thus encompassing the period when abnormally developing embryos perish. Indeed, after 79 days of incubation, only healthy embryos remained, which did not show any macroscopic symptoms of developmental disorders. These embryos would probably have hatched had the incubation conditions been appropriate at the end of the embryonic phase. Previous experience with the incubation of coregonid embryos in Zug jars under optimal flow-through conditions in the present facilities clearly demonstrated that mortality during hatching is almost insignificant compared with mortality during the early phases of development. Early embryonic mortality is thus considered a reliable measure of intrinsic genetic incompatibilities during early ontogeny. Intrinsic incompatibilities, however, may still manifest later in life, e.g. during first feeding or sexual maturation.

Hatched larvae were not reared any further; hence, possible roles of extrinsic post-zygotic incompatibility are not tested in this study. But, it is rather unlikely that such mechanisms might contribute appreciably to the reproductive isolation between $C$. wartmanni and C. macrophthalmus. Extrinsic incompatibilities have been 
shown for coregonids (Lu \& Bernatchez, 1998) and for gasterosteids (Rundle, 2002), but only between species or ecotypes that differ markedly in feeding habitats and thus main prey types, i.e. zooplankton $v$. zoobenthos. In these cases, F1 hybrids or backcrosses showed that intermediate phenotypes coped less well with conditions in the habitats of their parents than pure lineages. Such a mechanism is probably of little relevance in the case of $C$. wartmanni and $C$. macrophthalmus, however, because both are predominantly zooplanktivorous (Eckmann \& Rösch, 1998). Prior to anthropogenic eutrophication of their habitat, C. macrophthalmus had higher gill raker numbers than $C$. wartmanni $(41$ v. 36) (Steinmann, 1950), suggesting that $C$. macrophthalmus were slightly more efficient in feeding on small-sized zooplankton. In addition, their foraging grounds overlapped only little, $C$. wartmanni foraging in the pelagic zone and C. macrophthalmus in nearshore regions (Wagler, 1941). As a result of anthropogenic eutrophication, zooplankton abundance increased about four-fold in Upper Lake Constance, and both species co-occurred in the pelagic zone during the growing season. In parallel, the gill raker numbers of both species converged to around 35 (Vonlanthen et al., 2012), suggesting that under abundant food supply the species no longer benefitted from using different size classes of the zooplankton. Hence, there is no reason to suspect that the performance of hybrids with intermediate gill raker counts would have been inferior to that of pure progeny. Considering the still ongoing re-oligotrophication of Lake Constance, the feeding patterns of the two species might diverge again, leading to differences in gill raker counts and probably to reduced hybrid fitness.

The individual maternal effect on early embryonic mortality was very pronounced in C. macrophthalmus [Fig. 2(c), (d)] whereby embryos of females numbers 3 and 5 showed highest mortality rates in both homo and heterologous crosses. Furthermore, mortality rates of maternal siblings were rather uniform in both types of crosses, rejecting an interaction between individual females and males. In C. wartmanni, the maternal effect on early mortality was less pronounced, but still significant. In crosses with male C. macrophthalmus, mortality rates among maternal $C$. wartmanni siblings were similarly uniform to those of homo and heterologous maternal C. macrophthalmus siblings [Fig. 2(b)], but in crosses with male $C$. wartmanni, mortality rates among maternal siblings were more variable [Fig. 2(a)]. These observations suggest an asymmetric contribution of $C$. wartmanni and $C$. macrophthalmus males to early embryo mortality in this study: a weak contribution of $C$. macrophthalmus males in both homo and heterologous crosses, a weak effect of $C$. wartmanni males in heterologous crosses but a much more pronounced effect of $C$. wartmanni males in homologous crosses. This result, although statistically non-significant, appears counterintuitive and further study is required to gain more insight into the species- and individual-specific contributions of male coregonids to early embryo survival. $L_{\mathrm{T}}$ and mass at age of $C$. macrophthalmus spawners were markedly higher than in $C$. wartmanni spawners (Table I). This might be correlated with better sperm quality in the faster-growing species, a hypothesis that needs to be tested with spawners of variable sizes and ages. In any case, paternal effects on hatching success such as those found in north-west Atlantic cod Gadus morhua L. 1758 (Trippel \& Morgan, 1994) and Atlantic haddock Melanogrammus aeglefinus (L. 1758) (Probst et al., 2006), for example, were not apparent in this study.

The main results of this study support the hypothesis that the coregonid species of sympatric origin are reproductively isolated primarily by pre-zygotic barriers such as spawning time and place (Schluter, 2009). Therefore, when the environmental 

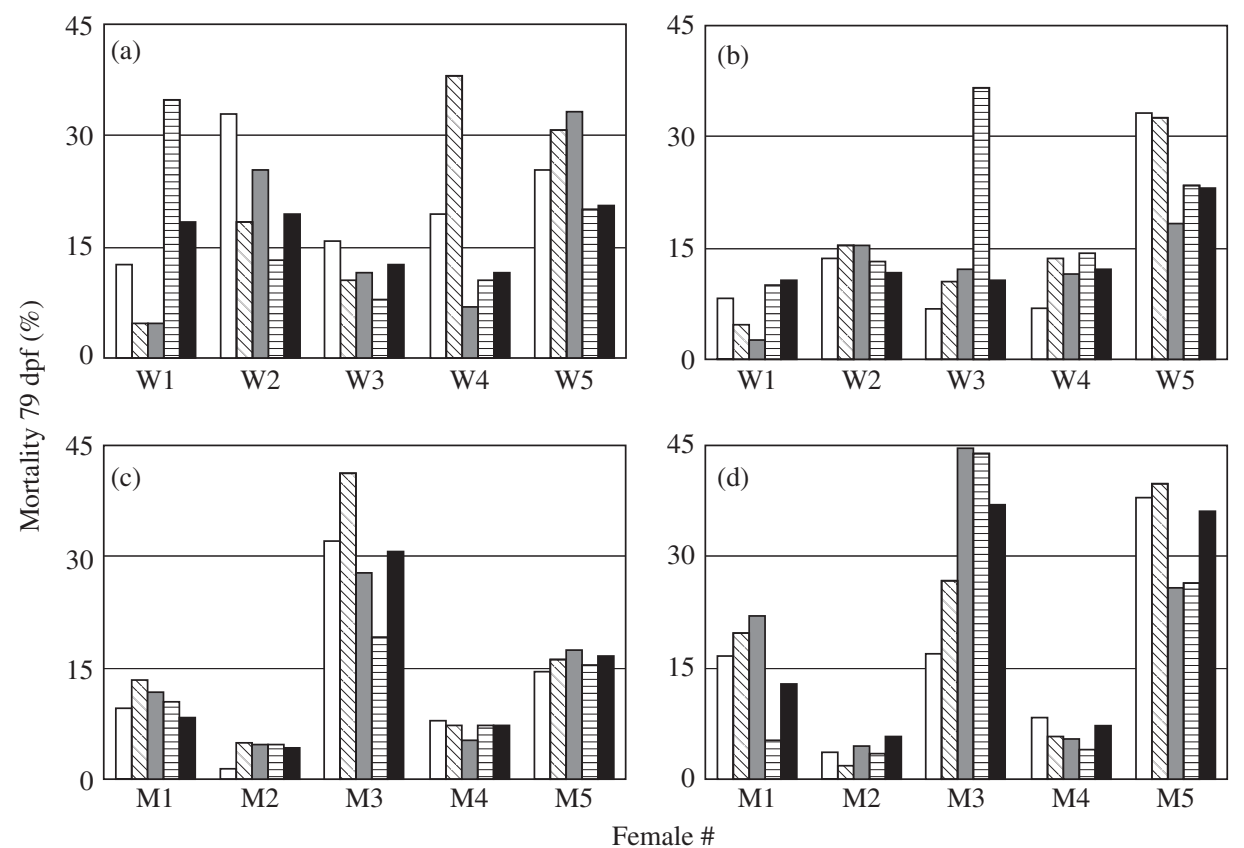

FIG. 2. (a) Cumulative mortality on day 79 post-fertilization (dpf) of embryos from five Coregonus wartmanni females (W1-W5) fertilized with milt from five C. wartmanni males or (b) five Coregonus macrophthalmus males and (c) the same for embryos from five C. macrophthalmus females (M1-M5) fertilized with milt from five C. macrophthalmus males or (d) five $C$. wartmanni males. In each panel, the five males are depicted by different column patterns.

conditions that maintained reproductive isolation of sympatric species are relaxed, introgression is not inhibited by genetic mechanisms, and recently diverged species may go extinct by speciation reversal. This is likely to have happened in Lake Constance during the second half of the 20th century, when anthropogenic eutrophication led to $C$. wartmanni and $C$. macrophthalmus congregating in the pelagic zone to capitalize on the abundant zooplankton production. Despite regular monitoring of the Lake Constance coregonids, which is particularly intense around spawning time in late November and early December, no changes in the respective spawning behaviour were detected, suggesting that each species still used its own distinct spawning habitat. Indeed, the fishes were still harvested in large quantities from their respective spawning places during the 1970s and 1980s when eutrophication of the lake was at its peak (catch statistics archived at the Fisheries Research Station of Baden-Wuerttemberg at Langenargen). Introgression between the two species, however, must have occurred during that time, as evidenced by the decline of pair-wise $F_{\text {st }}$ values (Vonlanthen et al., 2012).

Given the apparent lack of direct evidence for introgression during natural reproduction of coregonids in Lake Constance, the possible effects of the decade-long practice of stocking on the genetic separation of the two species needs to be considered. During the second half of the 20th century, coincident with anthropogenic eutrophication, significant quantities of up to $7 \times 10^{3}$ larvae ha $^{-1}$ began to be stocked every year (Eckmann, 2012). Until the early 1990s, fishing for C. wartmanni and C. macrophthalmus 
spawners often took place on the same calendar days. Fishermen did not hesitate to fertilize $C$. wartmanni eggs with milt from $C$. macrophthalmus males and vice versa whenever homologous males were in short supply. Through this practice, which was only halted in the 1990s when the spawning fisheries for the two species began to be held on separate days, man-made introgression between species has definitely occurred. The relative contributions of eutrophication-mediated and man-made introgression to the genetic homogenization of $C$. wartmanni and C. macrophthalmus, however, have not yet been thoroughly evaluated.

The apparent absence of intrinsic post-zygotic incompatibilities between $C$. wartmanni and C. macrophthalmus found in this study may partly result from increased gene flow between these species since the peak of eutrophication and the establishment of intensive stocking. Both factors, however, affected the species during the last three decades only, corresponding to $c .10$ generations. Even though previously existing incompatibilities might have been attenuated during this time, they cannot have been very pronounced and subsequently disappeared after only 10 generations of increased gene flow. Hence, the apparent absence of incompatibilities found in this study may not mirror exactly the level of intrinsic post-zygotic incompatibilities that existed prior to the recent genetic homogenization among Lake Constance coregonids. They can, however, be considered as representative of the low level of genetic incompatibilities between these recently diverged species, underlining again the importance of pre-zygotic barriers in maintaining diversity among coregonid species flocks.

To safeguard species diversity among sympatric coregonids, two measures need to be taken, first maintaining or restoring the conditions that led to sympatric speciation and second evaluating and where necessary modifying stocking practices in order to avoid introgression during artificial fertilization. The first measure, aiming at providing the adaptive landscape that prevailed for thousands of years and allowed for extremely rapid speciation in perialpine lake coregonids, is accomplished or at least underway in most European perialpine lakes. When the first signs of anthropogenic eutrophication were noted in the 1950s, appropriate countermeasures were taken and as a result, nutrient (i.e. phosphate) levels started to decline in the 1980s, and by the early $2000 \mathrm{~s}$ many coregonid lakes north of the European Alps had returned to near-pristine levels of phosphate concentration.

The second measure has also already been partly accomplished at Lake Constance by fishing for only one species per night during the spawning fishery. But, it is not just genetic homogenization between species that needs to be avoided; the fine-scale differentiation within species is also a component of biodiversity worth conserving. For example, a recent study has demonstrated a subtle but ecologically relevant diversity between $C$. macrophthalmus spawning in the shore region at depths from 2 to $50 \mathrm{~m}$ (Hirsch et al., 2013). This diversity, from which a further differentiation might arise under the recently re-established oligotrophic lake conditions, is potentially threatened by a stocking practice that considers $C$. macrophthalmus from all depths as one homogeneous management unit. This study highlights once more the importance of pre-zygotic barriers for species and ecotype diversity in sympatric coregonids and underlines the need for a thorough re-evaluation of traditional management practices.

Many thanks to my technical assistant M. Schmid for her meticulous care of the embryos and for all measurements on eggs and larvae. K. Gerber and S. O'Leary helped with the daily control of the embryos. J. Behrmann-Godel made valuable comments on a first manuscript version. A. -J. Beer improved the English language of this manuscript. 


\section{References}

Chambers, R. C. \& Leggett, W. C. (1996). Maternal influences on variation in egg sizes in temperate marine fishes. American Zoologist 36, 180-196.

Douglas, M. R., Brunner, P. C. \& Bernatchez, L. (1999). Do assemblages of Coregonus (Teleostei: Salmoniformes) in the Central Alpine region of Europe represent species flocks? Molecular Ecology 8, 589-603.

Eckmann, R. (2012). Massive stocking with hatchery larvae may constrain natural recruitment of whitefish stocks and induce unwanted evolutionary changes. Fundamental and Applied Limnology, Special Issues Advances in Limnology 63, 325-336.

Eckmann, R. \& Rösch, R. (1998). Lake Constance fisheries and fish ecology. Archiv für Hydrobiologie, Special Issues Advances in Limnology 53, 285-301.

Hirsch, P. E., Eckmann, R., Oppelt, C. \& Behrmann-Godel, J. (2013). Phenotypic and genetic divergence within a single whitefish form - detecting the potential for future divergence. Evolutionary Applications 6, 1119-1132.

Hudson, A. G., Vonlanthen, P. \& Seehausen, O. (2011). Rapid parallel adaptive radiations from a single hybridogenic ancestral population. Proceedings of the Royal Society B 278, 58-66.

Huuskonen, H., Haakana, H. \& Kekalainen, J. (2009). Offspring performance is linked to parental identity and male breeding ornamentation in whitefish. Biological Journal of the Linnean Society 98, 532-539.

Keller, O. \& Krayss, E. (2000). Die Hydrographie des Bodenseeraums in Vergangenheit und Gegenwart. Berichte der St Gallischen Naturwissenschaftlichen Gesellschaft 89, 39-56.

Kroll, M. M., Peck, M. A., Butts, I. A. E. \& Trippel, E. A. (2013). Paternal effects on early life history traits in Northwest Atlantic cod, Gadus morhua. Journal of Applied Ichthyology 29, 623-629.

Lu, G. Q. \& Bernatchez, L. (1998). Experimental evidence for reduced hybrid viability between dwarf and normal ecotypes of lake whitefish (Coregonus clupeaformis Mitchill). Proceedings of the Royal Society B 265, 1025-1030.

Ostbye, K., Amundsen, P.-A., Bernatchez, L., Klemetsen, A., Knudsen, R., Kristoffersen, R., Naesje, T. F. \& Hindar, K. (2006). Parallel evolution of ecomorphological traits in the European whitefish Coregonus lavaretus (L.) species complex during postglacial times. Molecular Ecology 15, 3983-4001.

Pamminger-Lahnsteiner, B., Winkler, K. A., Weiss, S. \& Wanzenboeck, J. (2012). Does segregated spawning time prevent the introgression of stocked whitefish species into native species? A morphometric and genetic study in Lake Mondsee, Austria. Fundamental and Applied Limnology, Special Issues Advances in Limnology 63, 197-208.

Probst, W. N., Kraus, G., Rideout, R. M. \& Trippel, E. A. (2006). Parental effects on early life history traits of haddock Melanogrammus aeglefinus. ICES Journal of Marine Science 63, 224-234.

Rideout, R. M., Trippel, E. A. \& Litvak, M. K. (2004). Paternal effects on haddock early life history traits. Journal of Fish Biology 64, 695-701.

Rideout, R. M., Trippell, E. A. \& Litvak, M. K. (2005). Effects of egg size, food supply and spawning time on early life history success of haddock Melanogrammus aeglefinus. Marine Ecology Progress Series 285, 169-180.

Roesch, C., Lundsgaard-Hansen, B., Vonlanthen, P., Taverna, A. \& Seehausen, O. (2013). Experimental evidence for trait utility of gill raker number in adaptive radiation of a north temperate fish. Journal of Evolutionary Biology 26, 1578-1587.

Rogers, S. M. \& Bernatchez, L. (2006). The genetic basis of intrinsic and extrinsic post-zygotic reproductive isolation jointly promoting speciation in the lake whitefish species complex (Coregonus clupeaformis). Journal of Evolutionary Biology 19, 1979-1994.

Rojas-Beltran, R. \& Gillet, C. (1995). The quality of eggs and larvae of whitefish Coregonus lavaretus L. from Lake Léman: effect of female origin. Archiv für Hydrobiologie, Special Issues Advances in Limnology 46, 309-314.

Rundle, H. D. (2002). A test of ecologically dependent postmating isolation between sympatric sticklebacks. Evolution 56, 322-329.

Sarvala, J. \& Helminen, H. (1995). Significance of egg size variation in the year-class fluctuations of vendace (Coregonus albula). Archiv für Hydrobiologie, Special Issues Advances in Limnology 46, 187-194. 
Schluter, D. (2009). Evidence for ecological speciation and its alternative. Science 323, $737-741$.

Seehausen, O. (2006). Conservation: losing biodiversity by reverse speciation. Current Biology 16, R334-R337.

Steinmann, P. (1950). Monographie der Schweizerischen Koregonen. Beitrag zum Problem der Entstehung neuer Arten. Spezieller Teil. Schweizerische Zeitschrift für Hydrologie 12, 340-491.

Trippel, E. A. \& Morgan, M. J. (1994). Age-specific paternal influences on reproductive success in Atlantic cod (Gadus morhua L) of the Grand Banks, Newfoundland. ICES Marine Science Symposium 198, 414-422.

Vøllestad, L. A. \& Lillehammer, T. (2000). Individual variation in early life-history traits in brown trout. Ecology of Freshwater Fish 9, 242-247.

Vonlanthen, P., Roy, D., Hudson, A. G., Largiader, C. R., Bittner, D. \& Seehausen, O. (2009). Divergence along a steep ecological gradient in lake whitefish (Coregonus sp.). Journal of Evolutionary Biology 22, 498-514.

Vonlanthen, P., Bittner, D., Hudson, A. G., Young, K. A., Mueller, R., Lundsgaard-Hansen, B., Roy, D., Di Piazza, S., Largiader, C. R. \& Seehausen, O. (2012). Eutrophication causes speciation reversal in whitefish adaptive radiations. Nature 482, 357-362.

Wagler, E. (1941). Die Lachsartigen (Salmonidae), II. Teil, Coregonen. In Handbuch der Binnenfischerei Mitteleuropas (Demoll, R. \& Maier, H. N., eds), pp. 371-501. Stuttgart: E. Schweizerbart'sche Verlagsbuchhandlung.

Wedekind, C. \& Müller, R. (2004). Parental characteristics versus egg survival: towards an improved genetic management in the supportive breeding of lake whitefish. Annales Zoologici Fennici 41, 105-115.

Winkler, K. A., Pamminger-Lahnsteiner, B., Wanzenboeck, J. \& Weiss, S. (2011). Hybridization and restricted gene flow between native and introduced stocks of Alpine whitefish (Coregonus sp.) across multiple environments. Molecular Ecology 20, 456-472. 